Ross, J. A., Cousins, J.B. \& Gadalla, T. (1996). Within-teacher predictors of teacher efficacy. Teaching and Teacher Education, 12(4), 385-400.

\title{
WITHIN-TEACHER PREDICTORS OF TEACHER EFFICACY ${ }^{1}$
}

\author{
John A. Ross* \\ Ontario Institute for Studies in Education \\ J. Bradley Cousins \\ University of Ottawa \\ Tahany Gadalla \\ Ontario Institute for Studies in Education
}

September 1995

"Corresponding Author:

OISE Trent Valley Centre, Box 719, 150 O'Carroll Avenue,

Peterborough, Ontario, Canada, K9J 7A1 


\begin{abstract}
Previous research has represented teacher efficacy (TE) as a unitary disposition, despite theoretical arguments that TE is task specific. Experienced secondary teachers $(\underline{\mathrm{N}}=52)$ responded to a survey probing their feelings of personal efficacy toward teaching different classes (up to four per respondent). Teachers' performance expectancies varied among teaching assignments: Within-teacher factors accounted for $21 \%$ of the variance in TE. The influence of within-teacher factors on TE was moderated by between-teacher variables (subject, experience, education, gender, preference for student-directed instruction and innovative assessment).
\end{abstract}




\section{WITHIN-TEACHER PREDICTORS OF TEACHER EFFICACY ${ }^{1}$}

Teachers' confidence in their ability to perform the actions that lead to student learning is one of the few individual teacher characteristics that reliably predicts teacher practice and student outcomes (Authors, 1994a). This variable, typically labelled teacher efficacy (TE), is consistently associated with supervisor ratings of the effectiveness of experienced (Hoover-Dempsy, Bassler \& Brissie, 1987; Riggs \& Enochs, 1990; Trentham, Silvern \& Brogdon, 1985) and preservice teachers (Flowers, 1988; Saklofske, Michayluk \& Randhawa, 1988). Almost all previous studies have treated TE as if it were a global disposition, constant across teaching conditions. The purposes of this study were to find out if teachers' performance expectancies varied from one teaching situation to another; if they did, to determine whether the influence of within-teacher variables was constant across teachers; and if the influence of within-teacher factors varied, to identify the between-teacher factors associated with that variance.

\section{Theoretical Framework}

\section{$\underline{\text { Definition of Teacher Efficacy }}$}

Definitions of TE abound, each dependent to a lesser or greater degree upon Bandura's $(1977,1986,1993)$ definition of self-efficacy as a subject's judgment about his or her ability to complete a future action. Individuals who feel that they will be successful on a given task are more likely to be so because they adopt challenging goals, try harder to achieve them, persist despite setbacks, and develop coping mechanisms for managing their emotional states. Individuals who believe they will fail will avoid expending effort because failure after trying hard threatens self-esteem (Schunk, 1981). For Bandura self-efficacy is task-specific; it is not a generalized expectancy. It develops from a subject's appraisal of past experience with the task or with activities similar to it, although perceptions of efficacy can be modified by other sources of information such as observing the performances of others.

TE is a form of self-efficacy. We define it as an individual teacher's expectation that he or she will be able to bring about student learning. Our definition is congruent with the construct "personal teaching efficacy" adopted by other researchers (e.g., Gibson \& Dembo, 1984). It can be distinguished from other constructs in the same domain. (a) "General teaching efficacy" (Woolfolk, Rosoff \& Hoy, 1990) refers to the belief that the teacher 
population is able to bring about student change despite out-of-school constraints. It is a form of TE but it is empirically distinct, correlating weakly or not at all with personal TE (e.g., Authors, 1992; 1994b). General teaching efficacy is the belief that students are teachable. It does not specify who might be capable of doing so. Nor does it specify the means. (b) "Teacher's outcome expectancies" refers to beliefs that particular teaching actions will lead to student success. It differs from personal TE in that the teacher holding the belief does not necessarily believe that he or she is able to perform the actions thought to be productive. General teaching efficacy can be viewed as the sum of the teacher's outcome expectancies and many researchers treat general teaching efficacy and teacher's outcome expectancies as equivalent. (c) "Teacher locus of control" refers to teachers' willingness to attribute student outcomes to their own performance. It is moderately correlated with TE--internals are more likely to have higher personal TE (Hall, Hines, Bacon \& Koulianos, 1992)--and some researchers (e.g., Guskey, 1982) define efficacy exclusively as willingness to take responsibility for student successes and failures. Locus of control differs from personal TE in that taking responsibility for outcomes does not mean that one anticipates that the outcomes will be positive. A teacher might have an internal locus of control grounded in an inability to perform teaching actions effectively (Smylie, 1990).

Within-Teacher Variation in Teacher Efficacy

Although Bandura described self-efficacy as varying from one situation to another, a review of 87 empirical studies of TE (Authors, 1994a) found that almost all researchers represented TE as a single score aggregated over a variety of teaching conditions. Only two studies focused on differences within teachers.

Benz, Bradley, Alderman and Flowers (1992) asked experienced and preservice teachers to rate their effectiveness in handling typical teaching tasks described in 15 vignettes. In previous studies (Ashton, Webb \& Doda, 1983; Flowers, 1988) vignette responses were summed to produce a total score. Benz et al. examined each item separately, finding that teachers varied their responses to the vignettes and that these within-teacher differences were associated with a between-teacher factor, experience. Preservice teachers were more confident than experienced teachers with respect to vignettes involving student motivation but the opposite was the case for situations that called for a larger knowledge base, such as planning and evaluating lessons.

Raudenbush, Rowan, and Cheong (1992) asked a sample of secondary teachers how successful they thought they were in each of their classes. Although "judgments of self-efficacy are not mere reflections of past 
performance" (Schunk, 1982, p. 554), past success could be viewed as a proxy for TE because such appraisals are the most important source of information about self-efficacy (Bandura, 1993). Raudenbush et al. found that $44 \%$ of the variance in TE was attributable to within-teacher factors. Higher efficacy was reported for classes that contained students who were highly engaged, for which teachers felt well-prepared, that were at a higher track and grade, and had larger class size. Raudenbush et al. found the influence of these within-teacher factors was moderated by between-teacher differences in subject background and organizational context.

Our research was motivated by the paucity of studies investigating within-teacher variations in TE. We were guided by two questions:

1. Does TE vary within individuals? We focused on selected features of the classes which were assigned to teachers, rather than on other aspects of the teacher's role outside the classroom (such as extra-curricular duties) or on specific dimensions of teaching that cut across classes (such as formulating learning objectives).

2. Is the strength of within-teacher influences on TE moderated by between-teacher variables? We selected a few demographic, teaching practice, and organizational factors that were empirically promising and theoretically interesting.

Dependent Variable

The dependent variable was personal teaching efficacy. It has been measured in a variety of ways, most convincingly as a battery of items focused on teacher expectations about their ability to perform specific teaching acts in a particular curriculum context (e.g., Mesquita \& Drake, 1994). But asking teachers to complete a lengthy instrument separately for each class they teach risks respondent fatigue. After searching previous studies for an efficient measure we selected an item originally developed for the Rand studies of school change: "If I try really hard I can get through to even the most difficult or unmotivated students in this class" (Armor et al., 1976). Although it has been described as crude (Guskey \& Passaro, 1994), it predicts scores on lengthier instruments (e.g., Gibson \& Dembo, 1984) and continues to be used extensively in TE research.

\section{Within-Teacher Variables}

In Bandura's (1986) theory the most important influence on perceived self-efficacy is the subject's interpretation of attempts to perform the desired actions. If these attempts are viewed as being successful, expectations for the future will likely be positive. We predicted that the teacher's feelings of past success would 
vary between classes and that teachers would have higher TE in those classes in which they were experiencing success.

Our second within-teacher variable was teacher feelings of being well-prepared, the extent to which s/he felt equipped with the tools needed to teach the class. The most important tool is specific course knowledge which includes understanding how the course structures facts, concepts and principles and how it determines the validity of knowledge. The most critical aspects are pedagogical content knowledge (Shulman, 1986): being able to anticipate student misconceptions and having strategies for transforming them into more accurate understandings. (Shulman's pedagogical content knowledge also includes the teacher's representation of the discipline for teaching, the strategies used to explain content.) Adequate preparation might influence TE by reducing teachers' uncertainty about their ability to perform the teaching behaviors required by the course. Rubeck and Enochs (1991) found that university coursework which was related to future teaching requirements predicted TE in that subject and some researchers (Brookhart \& Loadman, 1993; Housego, 1990, 1992) have used feeling prepared to teach as an indicator of (preservice) TE. We predicted that teachers would feel that their prior training and experience provided better preparation for some courses than others and that they would have higher TE when they felt well prepared.

Student engagement was the third within-teacher variable. Classes that are composed of students with low levels of interest in the course increase demands on teachers. Huberman (1992) found that generating and sustaining the interest of unmotivated pupils was perceived by teachers to be one of the most difficult facets of their work. Previous researchers have found that TE is higher among teachers with orderly students (Fletcher, 1990; Newmann, Rutter \& Smith, 1989) and that it decreases when teachers are given lower track classes (Raudenbush et al., 1992). We predicted that teacher perceptions of the extent to which their students were engaged by the lesson would vary between classes and that TE would be higher when teachers perceived student engagement to be higher.

\section{Between-Teacher Variables}

Although a large number of variables have been linked to TE (see Authors, 1994a for a review), we focused on a small number of demographic factors that were clearly antecedent and a few interesting variables in which the direction of causality could not be firmly established. Table 1 summarizes our predictions about how 
these between-teacher variables will moderate the influence of each within-teacher variable on TE.

\section{Table 1 About Here}

The first antecedent variable was subject discipline. Previous researchers have treated subject as a withinteacher factor. These studies used samples of generalist teachers: high school basic skills teachers (Ashton \& Webb, 1986) or grade 3 teachers (Watson, 1991). They found that personal teaching efficacy was associated with student achievement in language while achievement in math was linked to general teacher efficacy. We maintained a similar subject distinction (mathematics and science versus English, social studies, and art) but treated subject as a between-teacher variable because our sample of secondary teachers were specialists.

Our grounds for anticipating that subject would moderate the effect of within-teacher variables on TE was based on differences in the structure of the disciplines that require different teaching techniques (Stodolsky, 1988). In mathematics, and to a lesser extent science, the sequence of learning objectives is well-specified (Ma \& Lauman, 1994) and the sources of student difficulty are well known (Putnam, Lampert \& Peterson, 1990), factors that would increase the predictability of teaching: The strategy successfully implemented this week is likely to be implemented with equal ease the next. We predicted that the influence of feelings of past success on TE would be stronger for math/science teachers because the greater predictability of their subjects increased the likelihood that present trends in the classroom would continue.

Predictability should also increase the value of preparation. The match between skills anticipated and skills actually required is likely to be higher if the problems to be addressed are recurrent and relatively well bounded. We predicted that the influence of teachers' feelings of being prepared to teach the course on TE would be stronger for mathematics/science teachers.

Teaching styles also differ between subjects. For example, Resnick (1988) found that reciprocal teaching techniques developed in English did not transfer easily to math. Specialist teachers of mathematics and science believe that massed practice is essential to learning, a view that is especially strong for teachers who think that the development of skills is analogous to strengthening a muscle (Eisenhart et al., 1993). A mathematics/science teacher facing an unmotivated class might feel more taxed than a teacher of a subject in which repetitive practice is less central. We predicted that the influence of perceived student engagement on TE would be stronger for math/science teachers. 
These predictions about the between-teacher effects of subject discipline may be less credible for teachers who represent mathematics and science as ill-structure disciplines (Resnick, 1988). But implementation of this conception of mathematics and science has been rare; traditional conceptions prevail in most secondary schools.

The second antecedent variable was teaching experience. Teachers' TE increases with experience (Dembo \& Gibson, 1985; Hoy \& Woolfolk, 1993; Rubeck \& Enochs, 1991), particularly during the preservice year(s) (Cannon, 1992; Housego, 1990; Hoy \& Woolfolk, 1990). Future expectancies are likely to be more firmly based on past experience when the bank of past experiences is greater. For that reason we predicted that the influence of feelings of success on TE would be stronger for more experienced teachers. We also predicted that the influence of preparedness on TE would be stronger for experienced teachers. Our reasoning was that novices have difficulty selecting appropriate explanatory examples in all their courses but experienced teachers encounter this problem only when they lack subject background (Sanders, Borko, \& Lockard, 1993). We predicted that the TE of inexperienced teachers would be more influenced by perceptions of student engagement because the early years of teaching are marked by concerns about student management (Fuller, 1969) and inexperienced teachers lack strategies for keeping students engaged (Schaffer, Stringfield, \& Wolfe, 1992).

The third between-teacher factor was education. Teachers with a graduate degree are more likely to have higher TE than those who do not (Hoover-Dempsey et al., 1987; Hoy \& Woolfolk, 1993), most likely because extended training contributes to the acquisition of new teaching skills and the strengthening of teachers' appreciation of the potency of new techniques. A graduate program might make teachers more aware of the many factors that impinge upon teaching effectiveness, thereby depressing teachers' expectation that the future would be like the past. We predicted that the influence of feelings of success on TE would be weaker for teachers with a graduate degree. On the other hand, feelings of being well-prepared would have a greater influence on TE for those with a graduate degree if their degree program provided them with enhanced curriculum planning skills. A graduate program might also make teachers more aware of the impact of student engagement on learning and the importance of considering student motivation when planning instruction.

The fourth antecedent variable was gender. Females report higher TE than males (Anderson, Greene \& Lowen, 1988; Evans \& Tribble, 1986; Greenwood, Olejnick \& Parkay, 1990; Lee, Buck \& Midgley, 1992; Raudenbush et al., 1992) ${ }^{2}$, possibly because teaching is viewed as a female occupation (Apple \& Jungck, 1992) and 
females are more satisfied with teaching. We predicted that the influence of feelings of success on TE would be stronger for females because the beliefs of women teachers are more in tune with the dominant ideology of schools, such as a commitment to student centered approaches (Kalaian \& Freeman, 1994). We predicted that the influence of preparedness on TE would be stronger for men because (and this is very speculative) from one feminist perspective, men have "an over-confident reliance on the power of rationality to predict accurately effect from cause" (Robertson, 1992, p. 43). We predicted that the influence of student engagement on TE would be stronger for female teachers because women identify nurturing of children as their prime motivation for entry to the profession (Lortie, 1975) and they are more willing to accept responsibility for exceptional pupils (Kalaian \& Freeman, 1994).

The remaining between-teacher variables were less obviously antecedent and an argument could easily be made that the relationships are reciprocal. The first item in this set was teacher perceptions that their school was a learning organization. Supportive organizational cultures contribute to TE by creating opportunities for teachers to (a) vicariously benefit from the successful experiences of peers, and (b) be persuaded of their own competence through feedback from supervisors (e.g., in clinical supervision models) and colleagues (e.g., in joint planning activities). Such opportunities enable teachers to engage in social processing activities (Louis, 1994) and to develop shared understandings of teaching and learning phenomena and curriculum implementation processes. Vicarious experience and persuasion are key factors contributing to self-efficacy (Bandura, 1986). Other school practices that might contribute to greater TE are the encouragement of risk taking and norms about accepting responsibility for student outcomes. Higher TE is associated with teacher collaboration (Authors, 1992; HooverDempsey et al., 1987; Miskel, McDonald \& Bloom, 1983; Moore \& Esselman, 1992; Raudenbush et al., 1992; Rosenholtz, 1989), involvement in school decision-making (Berman et al., 1977; Fletcher, 1990; Moore \& Esselman, 1992; Raudenbush et al., 1992), and participation in in-service training programs (Authors, 1994b; Bolinger, 1988; Dutton, 1990; Ohmart, 1992; Stein \& Wang, 1988).

We predicted that perceived success would be more strongly linked to TE for teachers who belonged to organizations with more favorable learning cultures because they would be more likely to develop (through social interaction) expanded conceptions of classroom success. Similarly, the reduced isolation from peers associated with joint planning and implementation activities would be likely to foster a form of peer pressure to keep abreast 
of recent disciplinary developments or to otherwise "know your stuff". We predicted that organizational cultures that support such opportunities would strengthen the relationship between preparedness and TE. Finally, teachers working in supportive organizational learning cultures are more likely to have developed through social processing deeper understandings of the importance of student motivation to the teaching and learning process and we expected a stronger relationship between student engagement and TE for such teachers.

The next item in this set was preference for student directed teaching strategies. High self-efficacy encourages risk taking by reducing fear of failure. Teachers with high TE are more likely to use high risk instructional strategies which require the teacher to share classroom control with students. These include small group techniques (Tracs \& Gibson, 1986), cooperative learning (Dutton, 1990), and activity based methods (Czerniak \& Schriver-Waldon, 1991; Riggs \& Enochs, 1990). These teachers are less likely to rely on lower risk teacher-dominant approaches such as whole class teaching (Ashton \& Webb, 1986; Tracs \& Gibson, 1986).

We predicted that teachers who prefer student-directed teaching strategies would be less influenced by past success because giving students greater control of the classroom agenda lessens the predictability of student responses and reduces teacher expectations that they will be able to perform in the future as in the past. For the same reason, we predicted that the influence of preparedness would decrease for these teachers because the perceived utility of preparation is reduced when opportunities to exercise it cannot be anticipated.

Our reasoning about the moderating effect of teaching strategies on the influence of student engagement was slightly different. In teacher-directed instruction, teachers have access to all students simultaneously and the teacher controls classroom talk. Student engagement is more visibly related to teacher actions than in instructional approaches (such as group work) in which student engagement is less teacher dependent. We predicted that the influence of student engagement would have a weaker influence on the confidence of teachers using studentdirected teaching strategies.

The other teacher practice variable involving risk taking was preference for innovative assessment practices. Vitali (1993) found that high TE teachers were more likely to rely on performance-based assessments of student work rather than on more traditional tests. Performance based assessment is an ongoing formative process occurring during teaching rather than a summative event (Frederickson \& Collins, 1989). Innovative assessment practices increase the unpredictability of the classroom by generating information for immediate use. We predicted 
that because of this increased unpredictability, the TE of teachers using innovative assessment would be less influenced by past success than teachers using traditional assessment methods. A preference for innovative assessment might accentuate the value of pedagogical content knowledge (reflected in the within-teacher variable, preparedness). Knowing when potential learning difficulties are likely to occur and the form they might take focuses teachers' observations and sharpens their assessment probes. We predicted that preference for innovative assessment would strengthen the influence of feelings of course preparedness on TE. We predicted that the relationship of perceptions of student engagement and TE would not be moderated by assessment preferences because we could see no theoretical linkages that would warrant predicting otherwise.

\section{METHOD}

$\underline{\text { Sample }}$

Data were obtained from a convenience sample of secondary school teachers from several school districts in a predominantly rural (two cities had populations of 65 000) and geographically dispersed (covering about 9000 sq. miles) region of east-central Ontario, Canada. All respondents were participants in regional inter-district inservice workshops held at different locations within the region. The data were collected prior to the commencement of workshop activities. The achieved sample was 92 teachers for which $51 \%$ were female and $29 \%$ had attained a Master's degree. The median years of teaching experience for the sample was 11-19 years. Participation in the data collection was voluntary. The achieved sample was representative of the provincial teacher population with regard to experience and gender (Ontario Ministry of Education, 1992; provincial data on graduate degrees are not available). For the purposes of the present analysis we used listwise deletion of missing data. This reduced the working sample to 52 . We had no reason to believe that the working sample of 52 differed in any systematic way from the deleted cases.

\section{$\underline{\text { Instrument }}$}

Data were collected using a four page questionnaire. Between-teacher data were teachers' ratings of school characteristics (12 items) and teaching and assessment strategies they used (18 items). Within-teacher variables consisted of the criterion measure of TE and three predictors. These variables, described in Table 2, were mostly teachers' ratings of agreement on a four-point Lickert-type scale. Teachers responded to four items (personal TE, preparedness, successfulness and student engagement) for up to four classes they taught and 
provided background information about themselves and their schools.

Table 2 about here

\section{Personal Teaching Efficacy (Criterion)}

We operationalized TE with an item originally developed for the Rand studies of school change: "If I try really hard I can get through to even the most difficult or unmotivated students in this class" (Armor et al., 1976). Since this construct was measured with a single item it was not possible to estimate its reliability. Within-Teacher Predictors

Teachers provided agreement ratings for each class in response to the following statements: "I feel well prepared to teach this class;" and "I feel successful teaching this class." Our measure of student engagement was a response to the question, "Approximately what percentage of the students in this class are actively engaged in the lesson on a typical day?" All three predictors were modelled after those used by Raudenbush et al. (1992). Not all of the teachers provided ratings of four classes. Many of the teachers in semestered schools taught only three classes per day. Again, since these constructs were measured with single items, reliability estimates were not possible.

\section{Between-teacher Predictors}

Characteristics of the eight between-teacher variables appear in Table 2. Some of these variables were based on teacher ratings on a five-point frequency scale ranging from "never" (1) to "always" (5).

"Organizational learning" was measured with a 12-item scale (Authors, 1993) containing items such as "People in our school are inquiry focused," "Staff here are willing to try something new," "Staff participation in school-wide matters (e.g., committees, councils) helps to reduce information overload for the individual." Table 2 reveals that the internal consistency of the scale was impressive. It could be argued that organizational learning is a school- as opposed to teacher-level variable. We treated it as a between-teacher variable because the ratio of teachers to schools in our sample was substantially less than 3:1; the adverse effect of constrained variance was likely to be of little consequence.

We operationalized "teaching strategies" by having teachers rate their classroom practice according to a set of six non-traditional teaching strategies which increase student control of learning. Examples of these items (developed for the study) were "I use mixed-ability groups," "I use cooperative learning techniques (e.g., STAD, 
Jigsaw)," "I use peer tutoring techniques." We drew on items developed by Authors (1993) that were previously shown to be reliable measures of "student assessment strategies." The eight items selected included the following examples: "My assessment practices motivate learning," "I compare students' current performance to their previous level of performance," "I use non-test methods (e.g., observation, interview) for assessing student performance." Table 2 shows that the internal consistencies for teaching strategies and student assessment were adequate. Teacher background variables were years of teaching experience, teacher's gender, and formal education, each based on single items. Finally, we collapsed subject area taught into (1) predominantly mathematics or sciences and (2) predominantly English, social studies or art.

\section{Results}

Table 3 shows the intercorrelations among criterion and predictor variables. The remaining betweenteacher variables were excluded from Table 3 since they are categorical variables. The table reveals that the within-teacher variables were moderately correlated with one another, that between teacher variables were either correlated weakly or not at all with (1) within-teacher variables and (2) one another.

\section{Table 3 about here}

We used the computer program HLM/2L (Bryk, Raudenbush, Seltzer \& Congdon, 1989) to invoke twolevel hierarchical linear model analyses. This approach permitted the simultaneous estimation of between- and within-teacher effects on TE. These results confirm, first, that within-teacher variables plausibly represent different dimensions of an underlying construct of teacher efficacy, and second, that multicollinearity among between-teacher predictors does not pose a threat to interpretations of the ensuing regression analyses.

Following the approach adopted by Raudenbush et al. (1992), the within-teacher model specified predictors of intrateacher variation in TE and the coefficients of this model then became the dependent variables in the between-teacher model. The reader is referred to Raudenbush and Bryk (1988) for a comprehensive treatment of hierarchical linear models. Results of our main analyses appear in Tables 4 and 5.

\section{Table 4 about here}

\section{$\underline{\text { Base-Only Model }}$}

The first model presented is the base-only model which provides estimates of the variance associated with within- and between-teacher variation. The appropriate model is : 
where $(\text { TEACHER EFFICACY })_{\mathrm{ij}}$ is the teacher $j^{\prime}$ s perceived self-efficacy in the context of class ${ }_{\mathrm{i}}$; TBASE $_{\mathrm{j}}$ is teacher $j$ 's average self-efficacy across classes; and $e_{\mathrm{ij}}$ is the deviation from that teacher's mean of (TEACHER EFFICACY $)_{\mathrm{ij}}$. The variance of $e_{\mathrm{ij}}$ denoted $\sigma^{2}$ is the within-teacher variation in self-efficacy.

Table 4 (panel 1) shows that $21 \%$ of the explained variation in TE $[.145 /(.145+.544)]$ is contextually situated or classed as within-teacher variance. This finding suggests that a teachers' sense of efficacy is dependent upon the class within which they teach and replicates somewhat the findings reported by Raudenbush et al. (1992).

\section{Within-Teacher Prediction Model}

In the within-teacher model estimated, teachers' self-efficacy not only depends upon their base (mean), but on the within-teacher predictors entered into the model (preparedness, successfulness, student engagement). In this model, Equation 1 is expanded by introducing within-teacher predictor variables. The expanded withinteacher model is:

$(\text { TEACHER EFFICACY })_{\mathrm{ij}}=$ TBASE $_{\mathrm{j}}+\beta_{\mathrm{j} 1}(\text { PREPARE })_{\mathrm{ij}}+\beta_{\mathrm{j} 2}(\mathrm{SUCCESS})_{\mathrm{ij}}+\beta_{\mathrm{j} 3}\left(\right.$ ENGAGE $_{\mathrm{ij}}+e_{\mathrm{ij}}$ Equation 2 Specifically, the within-teacher predictors preparedness (PREPARE) $)_{\mathrm{ij}}$, successfulness (SUCCESS) ij $_{\mathrm{ij}}$ and student engagement (ENGAGE $)_{\mathrm{ij}}$ are used as predictors for the self-efficacy of teacher $j$ in class $i$. We predicted that the regression coefficients $\beta_{1}, \beta_{2}$, and $\beta_{3}$ would all be positive. In Equation 2 the variance of $\mathrm{a}_{\mathrm{ij}}$ denoted $\sigma^{2}$ now denotes the residual variance, that is, the within-teacher variance not explained by the within-teacher predictors.

In this model, although we observed positive regression coefficients for each predictor (Table 4, panel 2), ${ }^{3}$ teachers' perceived preparedness and successfulness within classes did not explain significant proportions of the variation in TE. Teachers' self-efficacy was associated with higher proportions of classes believed to be engaged in instructional activities. The change in within-teacher variance in this model reveals that the predictors account for $13 \%$ of the within-teacher variation in efficacy [1-(.126/.145)].

\section{Between-Teacher Predictor Model}

Table 5 shows the results of regressing within-teacher slopes on the between-teacher predictors. In this model TBASE $\mathrm{j}$ is now the adjusted mean (expected value of self-efficacy for teacher $j$ ) controlling for 
$(\text { PREPARE })_{\mathrm{ij}}$, (SUCCESS $)_{\mathrm{ij}}$ and (ENGAGE $)_{\mathrm{ij}}$. Four equations were estimated:

$$
\begin{array}{lr}
\text { TBASE } \left._{\mathrm{j}}=\mathrm{BASE}+f \text { (between-teacher variables }\right)+u_{\mathrm{j}} & \text { Equation } 3 \\
\beta_{\mathrm{j} 1}=\mathrm{BASE}+f \text { (between-teacher variables) } & \text { Equation } 4 \\
\beta_{\mathrm{j} 2}=\mathrm{BASE}+f \text { (between-teacher variables) } & \text { Equation } 5 \\
\beta_{\mathrm{j} 3}=\mathrm{BASE}+f \text { (between-teacher variables) } & \text { Equation } 6
\end{array}
$$

In Equation 3, TBASE $\mathrm{j}_{\mathrm{j}}$ is the adjusted mean self-efficacy of teacher $j$ which depends upon the between teacher variables and a residual, $u_{\mathrm{j}}$. The variance of $u_{\mathrm{j}}, \tau^{2}$, when compared to $\tau^{2}$ of the base only model tells us the extent to which the teacher-level variables account for between-teacher variation. Equations 4 through six now formulate the respective regression coefficients $\beta_{\mathrm{j} 1}, \beta_{\mathrm{j} 2}$ and $\beta_{\mathrm{j} 3}$ as the criterion variables.

\section{Table 5 about here}

This model yielded several interesting findings; only between-teacher predictors achieving statistical significance are reported. Table 5 shows that none of the between-teacher predictors were associated with teachers' average perception of self-efficacy, but that several of these variables predicted the observed within-teacher slopes. The findings reveal that mathematics and science teachers were more likely to maintain perceptions of self-efficacy grounded in their level of preparation to teach these classes and in the extent to which they perceived students to be engaged within classes. On the other hand, teachers of English, social sciences and arts were more inclined to define efficacy according to their perceptions of success within the class.

The distinction between high school teachers who tended to define self-efficacy in terms of perceived success as contrasted with those who defined it in terms of preparedness and student engagement was not limited to the subject area taught. Teachers for whom perceived success was positively associated with self-efficacy were more likely to be women and to hold a Master's degree. These teachers were also less likely to report using nontraditional student assessment methods. On the other hand, to the extent that self-efficacy was reflected in feelings of preparedness, teachers tended to be male, to be more likely to adhere to principles of non-traditional student assessment, to be more experienced and to be less likely to engage in non-traditional teaching strategies. Finally, the portion of self-efficacy associated with perceived student engagement within classes was associated with teachers who tended to view their schools as learning organizations, although they were not inclined to hold 
Master's degrees or to engage in non-traditional teaching activities.

Table 6 summarizes the results in the format of the predictions of Table 1. Of the 21 predictions in Table 1, 14 were supported, 6 were not supported, and one was rejected.

\section{Discussion}

Our study contributes to TE research in two ways. First, it supports the theoretical claim that TE is a specific rather than a generalized expectancy by demonstrating that TE varies within teachers, a finding reached earlier by Raudenbush et al. (1992).

Although the three within-teacher variables we examined each correlated with TE, only teacher perception of student engagement was a significant predictor. Raudenbush et al. analyzed their data separately, with and without engagement in the equation, finding that the effect of other within-teacher variables (class size, track, and grade) was greatly diminished when engagement was included. Only teacher preparation could not be accounted for by engagement. The proportion of the variance in TE scores attributable to within-teacher variables was $21 \%$ in our study compared to $44 \%$ reported by Raudenbush et al. (1992). The simplest explanation for the difference is that their sample size was much larger (315 teachers to our 52). Contextual differences between schools in Michigan and our study in the province of Ontario might also have played a role. For example, a majority of secondary schools in our sample were semestered, which reduces the number of students each teacher meets each day by half and doubles the time spent with each class.

Our conclusion is limited by the method we used to reach it. HLM, is one of "the linear additive, unidirectional models that are the stock in trade of the quantitative social scientist", decried by Bryk \& Hermanson (1993) as "too simplistic a representation for the phenomena under study" [p. 471]. Our claims are weakened by our failure to deal with more complex interactions in the relationships among TE and our within-teacher variables. For example, the relationship between TE and feelings of success is probably reciprocal. In Bandura's theory selfefficacy contributes to subjects' success through goal setting processes. Those with higher self-efficacy set loftier standards of performance for themselves, accept responsibility if targets are not met, and respond to failure with renewed effort. Expectations of competence induce behaviors that lead to success. In the case of teachers, those with higher TE set more ambitious standards for themselves, for example, by focusing on student development rather than on content coverage (Brookhart \& Loadman, 1993), and for their students, for example, by promoting 
student self-management rather than relying on custodial methods of control (Midgley, Feldlaufer, \& Eccles, 1988; Woolfolk, Rosoff, \& Hoy, 1990). A similar argument can be made about the direction of causality linking TE and our between-teacher variables. For example, the relationship between the teaching practice variables and TE is likely reciprocal. Higher TE encourages the establishment of higher professional goals, manifest as a willingness to try new teaching ideas (Berman, McLaughlin, Bass, Pauly \& Zellman, 1977; Guskey, 1988), which might lead to greater success in the classroom, which in turn stimulates higher TE.

Another limitation in our method was the use of self-administered questionnaires to measure TE and its within-teacher correlates. A more accurate reading of the subtle relationships among these constructs might have been obtained by interviewing teachers using open ended probes. Future researchers might ask teachers if their confidence in their ability to implement effective teaching methods varies from one class to another and if it does, to identify features of their classes that make a difference. We anticipate that such an inquiry would confirm that an individual's TE does fluctuate among teaching assignments but we suspect that the characteristics they identify might be a broader set than those investigated by ourselves and other researchers.

The second contribution of the study to our knowledge of TE is that it provides evidence that withinteacher variables do not have a constant effect across all teachers; their impact is moderated by between-teacher factors. Our predictions about the influence of teaching assignments on different categories of teachers were confirmed in large part. The one finding that was in the opposite direction concerned the influence of subject specialization. We argued that the greater predictability of mathematics and science would lead these teachers to anticipate that past success would continue in the future. But it was the English, social studies, and art teachers were more influenced by past success. We wonder whether these humanistic subjects might he characterized by greater emotionalism leading to a kind of "momentum" that carries over from one day to next.

The lack of support for six of our predictions might be due in part to the imprecision of the measurement strategies we used. We operationalized teaching experience as a set of chronological intervals rather than as a set of psychological categories. Huberman (1989) asked teachers of varying maturities to divide their careers into stages and to give labels to each. Although Huberman identified some common patterns, the sequences were neither invariant nor universal. The categories and the ages at which they appeared differed among teachers. Huberman (1992) recommended that career experiences be viewed as recursive spirals rather than temporal 
segments. Future researchers might find that teacher experience has a stronger influence if experience is represented as teacher perceived stage of development rather than as elapsed years.

Another measurement concern was the use of self-report data to operationalize the teacher practice variables. The mean scores were near the mid-points of each of the scales. But most schools are not learning organizations; they use student directed teaching methods less frequently than transmission approaches, and the movement toward performance assessments is slow. Responses to the teaching practice scales in our study may have been influenced by social desirability, particularly since triangulation studies (e.g., Hook \& Rosenshine, 1979) indicate that teachers' self-reported practices imperfectly represent their observed behavior.

Our study about within-teacher influences on TE suggest two directions for further work. The first is to search for additional within-teacher factors that affect the difficulty of particular teaching assignments, such as characteristics of students (special learning needs, including minority language groups), resource levels (equipment, texts, disposables), and district or state policies that have a differential effect on particular courses. Teacher concerns about specific duties of the teacher might provide a parallel framework for generating potential within-teacher predictors. Testing new predictors would provide a more comprehensive answer to the question of how important intra-teacher variation is.

The second direction is to develop strategies for helping preservice and experienced teachers take greater control of their TE. Attempts to increase TE have produced mixed results (reviewed in Authors, in press), in part because TE has been treated as a unitary construct and because teachers have been treated as subjects not coinvestigators. TE has a powerful effect on the goals that teachers set for themselves and how they interpret the outcomes of their actions. An alternate approach is to create school-university teams to help teachers acquire selfknowledge about their TE, identifying the personal conditions under which it increases and declines. Such selfknowledge could be used proactively to restructure their personal work spaces and reactively to recognize when impending changes in their work lives (such as a new teaching assignment) will threaten their TE and require compensatory actions to renew it. 


\section{References}

Anderson, R., Greene, M., \& Loewen, P. (1988). Relationships among teachers' and students' thinking skills sense of efficacy, and student achievement. Alberta Journal of Educational Research, $\underline{34}(2), 148-165$.

Apple, M., \& Jungck, S. (1992). You don't have to be a teacher to teach this unit: Teaching, technology and control in the classroom. In A. Hargreaves, \& M. Fullan (Eds.), Understanding teacher development (pp. 20-42). New York, NY: Teachers College Press.

Armor, D., Conry-Oseguera, P., Cox, M., King, N., McDonnell, L., Pascal, A., Pauly, E., \& Zellman, G. (1976). Analysis of the school preferred reading program in selected Los Angeles minority schools.. Santa Monica, CA: Rand Corporation.

Ashton, P., \& Webb, R. (1986). Making a difference: Teachers' sense of efficacy and student achievement. New York, NY: Longman.

Ashton, P., Webb, R., \& Doda, N. (1983). A study of teacher's sense of efficacy. Final report to the National Institute of Education, Executive Summary. Gainesville, FL: Florida University. (ERIC Document Reproduction Service No. ED 231 833)

Bandura, A. (1993). Perceived self-efficacy in cognitive development and functioning. Educational Psychologist, $\underline{28}(2), 117-148$.

Bandura, A. (1986). Social foundations of thought and action: A social cognitive theory. Englewood Cliffs, NJ: Prentice-Hall.

Bandura, A. (1977). Self-efficacy: Toward a unifying theory of behavioral change. Psychological Review, $\underline{84}$, $191-215$.

Benz, C., Bradley, L., Alderman, M., \& Flowers, M. (1992). Personal teaching efficacy: Developmental

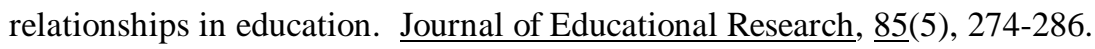

Berman, P., McLaughlin, W., Bass, G., Pauly, E., \& Zellman, G. (1977). Federal programs supporting educational change (Vol. VIII): Factors affecting implementation and continuation.. Santa Monica, CA: Rand Corporation.

Bolinger, R. (1988). The effects of instruction in the Hunter instructional model on teachers' sense of efficacy. Unpublished doctoral dissertation, Montana State University, Bozeman, Montana. UMI 8820177. 
Brookhart, S., \& Loadman, W. (1993). Relations between self- confidence and educational beliefs before and after teacher education. Paper presented at the annual meeting of the American Educational Research Association, Atlanta, GA.

Bryk, A., \& Hermanson, K. (1993). Educational indicator systems: Observations on their structure, interpretation and use. In L. Darling-Hammond (Ed.), Review of research in education (Volume 19) (pp. 451-484). Washington, DC: American Educational Research Association.

Bryk, A., Raudenbush, S., Seltzer, M., \& Congdon, R. (1989). An introduction to HLM: Computer program and user's guide. Chicago, IL: Scientific Software.

Cannon, J. (1992). Influence of cooperative early field experience on preservice elementary teachers' science selfefficacy. Unpublished doctoral dissertation, Kansas State University, Manhattan, Kansas. UMI 9235617.

Czerniak, C., \& Schriver-Waldon, M. (1991). A study of science teaching efficacy using qualitative and quantitative research methods. Paper presented at the annual meeting of the National Association for Research in Science Teaching, Lake Geneva, WI.

Dembo, M., \& Gibson, S. (1985). Teachers' sense of efficacy: An important factor in school achievement. Elementary School Journal, $\underline{\text { 86}}(2), 173-184$.

Dutton, M. (1990). An investigation of the relationship between training in cooperative learning and teacher job satisfaction. Unpublished doctoral dissertation, Portland State University, Portland, OR. UMI 90264940.

Eisenhart, M., Borko, H., Underhill, R., Brown, C., Jones, D., \& Agard, P. (1993). Conceptual knowledge falls through the cracks: Complexities of learning to teach mathematics for understanding. Journal for Research in Mathematics Education, 24(1), 8-20.

Evans, E., \& Tribble, M. (1986). Perceived teaching problems, self-efficacy, and commitment to teaching among preservice teachers. Journal of Educational Research, $\underline{80}(2), 81-85$.

Fletcher, S. (1990). The relation of the school environment to teacher efficacy. Paper presented at the annual meeting of the American Psychological Association, Boston, MA. (ERIC Document Reproduction Service No. ED 329 551)

Flowers, M. (1988). The role of preservice personal teaching efficacy in predicting microteaching success (initiating a discussion). Unpublished doctoral dissertation, University of Akron, Akron, OH. UMI 
8817642.

Fredericksen, J., \& Collins, A. (1989). A systems approach to educational testing. Educational Researcher, $\underline{18}(9)$, 27-32.

Fuller, F. (1969). Concerns of teachers. American Educational Research Journal, $\underline{6}(2)$, 207-226.

Gibson, S., \& Dembo, M. (1984). Teacher efficacy: A construct validation. Journal of Educational Psychology, $\underline{76}(4), 569-582$.

Greenwood, G., Olejnik, S., \& Parkay, F. (1990). Relationships between four teacher efficacy belief patterns and selected teacher characteristics. Journal of Research and Development Education, 23(2), 102-107.

Guskey, T. (1982). Differences in teachers' perceptions of personal control of positive versus negative student learning outcomes. Contemporary Educational Psychology, 7, 70-80.

Guskey, T. (1988). Teacher efficacy, self-concept, and attitudes toward the implementation of instructional innovation. Teaching and Teacher Education, 4(1), 63-69.

Guskey, T., \& Passaro, P. (1994). Teacher efficacy: A study of construct dimensions. American Educational Research Journal, 31(3), 627-643.

Hall, B., Hines, C., Bacon, T., \& Koulianos, G. (1992). Attributions that teachers hold to account for student

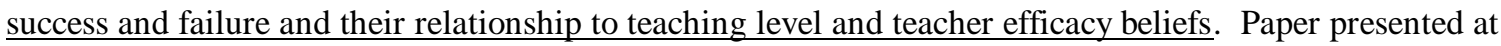
the annual meeting of the American Educational Research Association, San Francisco, CA.

Hook, C., \& Rosenshine, B. (1979). Accuracy of teacher reports of their classroom behavior. Review of $\underline{\text { Educational Research, }} \underline{49}, 1-12$.

Hoover-Dempsey, K., Bassler, O., \& Brissie, J. (1987). Parent involvement: Contributions of teacher efficacy, school socioeconomic status, and other school characteristics. American Educational Research Journal, $\underline{24}(3), 417-435$.

Housego, B. (1990). A comparative study of student teachers' feelings of preparedness to teach. Alberta Journal of Educational Research, 36(3), 417-240.

Housego, B. (1992). Monitoring student teachers' feelings of preparedness to teach, personal teaching efficacy, and teaching efficacy in a new secondary teacher education program. Alberta Journal of Educational Research, $\underline{38}(1), 49-64$. 
Hoy, W., \& Woolfolk, A. (1990). Socialization of student teachers. American Educational Research Journal, $\underline{27}(2), 279-300$.

Hoy, W., \& Woolfolk, A. (1993). Teachers' sense of efficacy and the organizational health of schools. Elementary School Journal, 93(4), 355-372.

Huberman, M. (1992). Teacher development and instructional mastery. In A. Hargreaves, \& M. Fullan (Eds.), Understanding teacher development (pp. 122-142). New York, NY: Teachers College Press.

Huberman, M. (1989). The professional life cycle of teachers. Teachers College Record, 91(3), 31-57.

Kalaian, H., \& Freeman, D. (1994). Gender differences in self- confidence and educational beliefs among secondary teacher candidates. Teaching and Teacher Education, 10(6), 647-658.

Lee, M., Buck, R., \& Midgley, C. (1992). The organizational context of personal teaching efficacy. Paper presented at the annual meeting of the American Educational Research Association, San Francisco, CA.

Leithwood, K., Cousins, J. B., \& Gérin-Lajoie, D. (1993). Years of transition, times for change: A review and analysis of pilot projects investigating issues in the Transition Years. Volume 2: Explaining variations in progress. Toronto: Queen's Printer for Ontario.

Lortie, D. (1975). School teacher: A sociology study. Chicago, IL: University of Chicago.

Louis, K. S. (1994). 'Beyond managed change': Rethinking how schools improve. School Effectiveness and School Improvement, $\underline{5}(1), 2-24$.

Ma, L., \& Lauman, B. (1994). Constraints on teaching for understanding in high school mathematics departments. Paper presented at the annual meeting of the American Educational Research Association, New Orleans, LA.

Mesquita, P., \& Drake, J. (1994). Educational reform and the self-efficacy beliefs of teachers implementing nongrade primary school programs. Teaching and Teacher Education, 10(3), 291-302.

Midgley, C., Feldlaufer, H., \& Eccles, J. (1989). Change in teacher efficacy and student self- and task-related beliefs in mathematics during the transition to junior high school. Journal of Educational Psychology, $\underline{81}(2), 247-258$.

Miskel, C., McDonald, D., \& Bloom, S. (1983). Structural and expectancy linkages within schools and organizational effectiveness. Educational Administration Quarterly, 19 (1), 49- 82. 
Moore, W., \& Esselman, M. (1992). Teacher efficacy, empowerment, and a focussed instructional climate: Does student achievement benefit? Paper presented at the annual meeting of the American Educational Research Association, San Francisco, CA.

Newmann, F., Rutter, R., \& Smith, M. (1989). Organizational factors that affect school sense of efficacy, community, and expectations. Sociology of Education, $\underline{62}, 221-238$.

Ohmart, H. (1992). The effects of an efficacy intervention on teachers' efficacy feelings. Unpublished doctoral dissertation, University of Kansas, Lawrence, Kansas. UMI 9313150.

Ontario Ministry of Education (1992). 1990-91 key statistics. Elementary and secondary education in Ontario. Toronto, ON: Ontario Ministry of Education.

Putnam, R., Lampert, M., \& Peterson, P. (1990). Alternate perspectives on knowing mathematics in elementary schools. In C. Cazden (Ed.), Review of Research in Education, Vol. 16 (pp. 57- 150). Washington, DC: American Educational Research Association.

Raudenbush, S., \& Bryk A. (1988). Methodological advances in analyzing the effects of schools and classrooms on school learning. Review of Research in Education, 15, 423-475.

Raudenbush, S., Rowan, B., \& Cheong, Y. (1992). Contextual effects on the self-perceived efficacy of high school teachers. Sociology of Education, $\underline{65}, 150-167$.

Raudenbush, S., Rowan, B., \& Cheong, Y. (1993). Higher order instructional goals in secondary schools: Class,

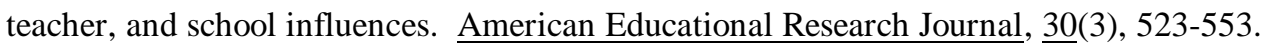

Resnick, L. (1988). Teaching mathematics as an ill-structured discipline. In R. Charles, \& E. Silver (Eds.), The teaching and assessing of mathematical problem solving (pp. 32-60). Hillsdale, NJ: Erlbaum.

Riggs, I. (1991). Gender differences in elementary science teacher self-efficacy. Paper presented at the annual meeting of the American Educational Research Association, Chicago, IL. (ERIC Document Reproduction Service No. ED 340 705)

Riggs, I., \& Enochs, L. (1990). Toward the development of an elementary teacher's science teaching efficacy belief instrument. Science Education, 74(6), 625-638.

Robertson, H. (1992). Teacher development and gender equity. In A. Hargreaves, \& M. Fullan (Eds.), Understanding teacher development (pp. 43-61). New York, NY: Teachers College Press. 
Rosenholtz, S. (1989). Teachers' workplace: The social organization of schools. New York, NY: Longman.

Ross, J. A. (1992). Teacher efficacy and the effect of coaching on student achievement. Canadian Journal of Education, $\underline{17}(1), 51-65$.

Ross, J. A. (1994a, June). Beliefs that make a difference: The origins and impacts of teacher efficacy. Paper presented at the annual meeting of the Canadian Society for the Study of Education, Calgary.

Ross, J. A. (1994b). The impact of an in-service to promote cooperative learning on the stability of teacher efficacy. Teaching and Teacher Education, 10(4), 381-394.

Ross, J. A. (in press). Strategies for enhancing teachers' beliefs in their effectiveness: Research on a school improvement hypothesis. Teachers College Record.

Rubeck, M., \& Enochs, L. (1991). A path analytic model of variables that influence science and chemistry teaching self- efficacy and outcome expectancy in middle school science teachers. Paper presented at the annual meeting of the National Association for Research in Science Teaching, Lake Geneva, WI.

Saklofske, D., Michayluk, J., \& Randhawa, B. (1988). Teachers' efficacy and teaching behaviors. Psychological Reports, $\underline{63}, 407-414$.

Sanders, L., Borko, H., \& Lockard, J. (1993). Secondary science teachers' knowledge base when teaching science courses in and out of their areas of certification. Journal of Research in Science Teaching, $\underline{30}(7)$, 723-736.

Schaffer, E., Stringfield, S., \& Wolfe, D. (1992). An innovative beginning induction program: A two-year analysis of classroom interactions. Journal of Teacher Education, $\underline{43}$ (3), 181-192.

Schunk, D. (1981). Modelling and attributional effects on children's achievement: A self-efficacy analysis. Journal of Educational Psychology, 73(1), 93-105.

Schunk, D. (1982). Effects of effort attributional feedback on children's perceived self-efficacy and achievement. Journal of Educational Psychology, 74(4), 548-556.

Shulman, L. (1986). Those who understand: Knowledge growth in teaching. Educational Researcher, 15(2), 4-14.

Smylie, M. (1990). Teacher efficacy at work. In P. Reyes (Ed.), Teachers and their workplace (pp. 48-66). Newbury Park, CA: Sage. 
Stein, M., \& Wang, M. (1988). Teacher development and school improvement: The process of teacher change. Teaching and Teacher Education, $\underline{4}(2), 171-187$.

Stodolsky, S. (1988). The subject matters: Classroom activity in math and social studies. Chicago, IL: University of Chicago Press.

Tracs, S., \& Gibson, S. (1986). Effects of efficacy on academic achievement. Paper presented at the annual meeting of the California Research Association, Marina del Rey, CA.

Trentham, L., Silvern, S., \& Brogdon, R. (1985). Teacher efficacy and teacher competency ratings. Psychology in the Schools, 2 , 343-352.

Vitali, G. (1993). Factors influencing teachers' assessment and instructional practices in an assessment-driven educational reform. Unpublished doctoral dissertation, University of Kentucky, Lexington, KY.

Watson, S. (1991). A study of the effects of teacher efficacy on the academic achievement of third-grade students in selected elementary schools in South Carolina. Unpublished doctoral dissertation, South Carolina State College, Orangebury, SC. UMI 9230552.

Woolfolk, A., Rosoff, B., \& Hoy, W. (1990). Teachers' sense of efficacy and their beliefs about managing students. Teaching and Teacher Education, $\underline{6}(2), 137-148$. 


\section{Reference Notes}

${ }^{1}$ The research was funded by the Ontario Ministry of Education of Training through a grant to the Ontario Institute of Education (\#81-1173) and by the Social Science and Humanities Research Council of Canada (\#41090-0834). The views expressed in the article do not necessarily represent the views of the Ministry or the Council. An earlier version of this article was presented at the annual meeting of the American Educational Research Association in San Francisco, April, 1995.

${ }^{2}$ Riggs (1991) found that males had higher TE than females but this finding was unique in focusing on efficacy in the context of science, a predominantly male domain.

${ }^{3}$ In this analysis each predictor was centered around its mean for a given teacher thereby restricting our interpretation to strictly within-teacher effects (Raudenbush et al., 1993). 